\title{
The Gastropod Statolith Elemental Composition by EMPA
}

\author{
S. Galante-Oliveira*, R. Marçal*, F. Guimarães**, J. Machado*** and C.M. Barroso* \\ *CESAM \& Biology Department, University of Aveiro, Campus Universitário de Santiago, 3810-193 \\ Aveiro, Portugal \\ **Unit of Science and Mineral Technology, National Laboratory of Energy and Geology (LNEG), R. da \\ Amieira, Apartado 1089, 4466-901 S. Mamede de Infesta, Portugal \\ ***Laboratory of Applied Physiology, Institute of Biomedical Sciences Abel Salazar (ICBAS), R. de \\ Jorge Viterbo Ferreira 228, 4050-313 Porto, Portugal
}

Gastropods statoliths are biogenic structures of $\mathrm{CaCO}_{3}$, analogous to fish otoliths [1]. Their application in sclerochronology is recent and may be advantageous comparing to the most traditional organisms used hitherto. Moreover, since elements bind within calcified structures [2], statoliths theoretically incorporate chemical information from the surrounding environment over time. So, besides being used for age estimation and growth studies [1], statoliths elemental fingerprinting is recognized as natural tag to track larval dispersal [2] and may also be considered as a potential marker of environmental change and/or pollution. However there is a lack of information on the elemental composition of adult gastropod statoliths. Here we characterize Nassariusreticulatus (Gastropoda: Caenogastropoda) statoliths elemental composition by electron microprobe analysis (EMPA).

One statolith from each of 3 adults was prepared for EMPA (Figure 1) and showed the same structural pattern: a nucleus circled by a metamorphic ring and, in addition to this core, 4 other rings delineating 5 increments (Figure 1F). General composition was assessed by Energy and Wavelength Dispersive Spectroscopy revealing $\mathrm{C}, \mathrm{Ca}, \mathrm{O}, \mathrm{Sr}, \mathrm{Na}, \mathrm{S}$ and $\mathrm{Mg}$ as the most representative elements. These were then quantified in 3 points per increment. Carbon was not determined since surfaces were C-coated and the amount of oxides of $\mathrm{Ca}, \mathrm{Sr}, \mathrm{Na}, \mathrm{S}$ and $\mathrm{Mg}$ was estimated from the valence. In addition, $\mathrm{Ba}$ - trace element in statoliths of some gastropods larvae [2] - and $\mathrm{Al}, \mathrm{Cu}, \mathrm{Hg}, \mathrm{Sn}$ - known as environmental pollutants were also sought in one of the statoliths. For such, mean values for $\mathrm{Ca}, \mathrm{Sr}, \mathrm{Na}, \mathrm{S}, \mathrm{Mg}$ and $\mathrm{O}$ were set as the sample matrix. Standards and mean detection limits by element and statolith are indicated in Table 1.

Concentrations of $\mathrm{Ca}, \mathrm{O}, \mathrm{Na}, \mathrm{Sr}$ and $\mathrm{S}$ varied between $3.7 \times 10^{5}-4.2 \times 10^{5}, 1.5 \times 10^{5}-1.7 \times 10^{5}, 2.5 \times 10^{3}-6.1 \times 10^{3}$, $1.3 \times 10^{3}-8.9 \times 10^{3}$ and $4.7 \times 10^{2}-1.3 \times 10^{3} \mathrm{ppm}$, respectively; $\mathrm{Mg}$, which was not always detected, ranged from $2.0 \times 10^{2}-8.6 \times 10^{2} \mathrm{ppm}$. No significant differences in these elements mean concentrations were found between increments, except $\mathrm{Na}$ in one statolith between increments 1 and 5 (higher at the edge; Dunn's test $s=2.014, \mathrm{p}<0.05$ ). Thus the general elemental composition is nearly constant throughout lifespan (i.e. along statoliths radiuses). Regarding trace elements: $\mathrm{Sn}$ was never detected; $\mathrm{Al}$ and $\mathrm{Hg}$ were at $22.2 \%$ of the punctual analyses conducted while $\mathrm{Cu}$ was at $66.7 \%$ and $\mathrm{Ba}$ at $88.9 \%$. Concentrations of $\mathrm{Al}, \mathrm{Hg}, \mathrm{Cu}$ and $\mathrm{Ba}$ varied between 55-71, 176-180, 183-302 and 647-969 ppm, respectively.

EMPA proved to be a useful technique in sclerochronology, allowing the characterization of the overall composition of gastropods statoliths and the quantification of elements in specific locations with high resolution.

References

1. Barroso C.M. et al., Mar. Biol., 146:1139, 2005

2. Lloyd D.C. et al., Mar Ecol. Prog. Ser., 353:115, 2008 

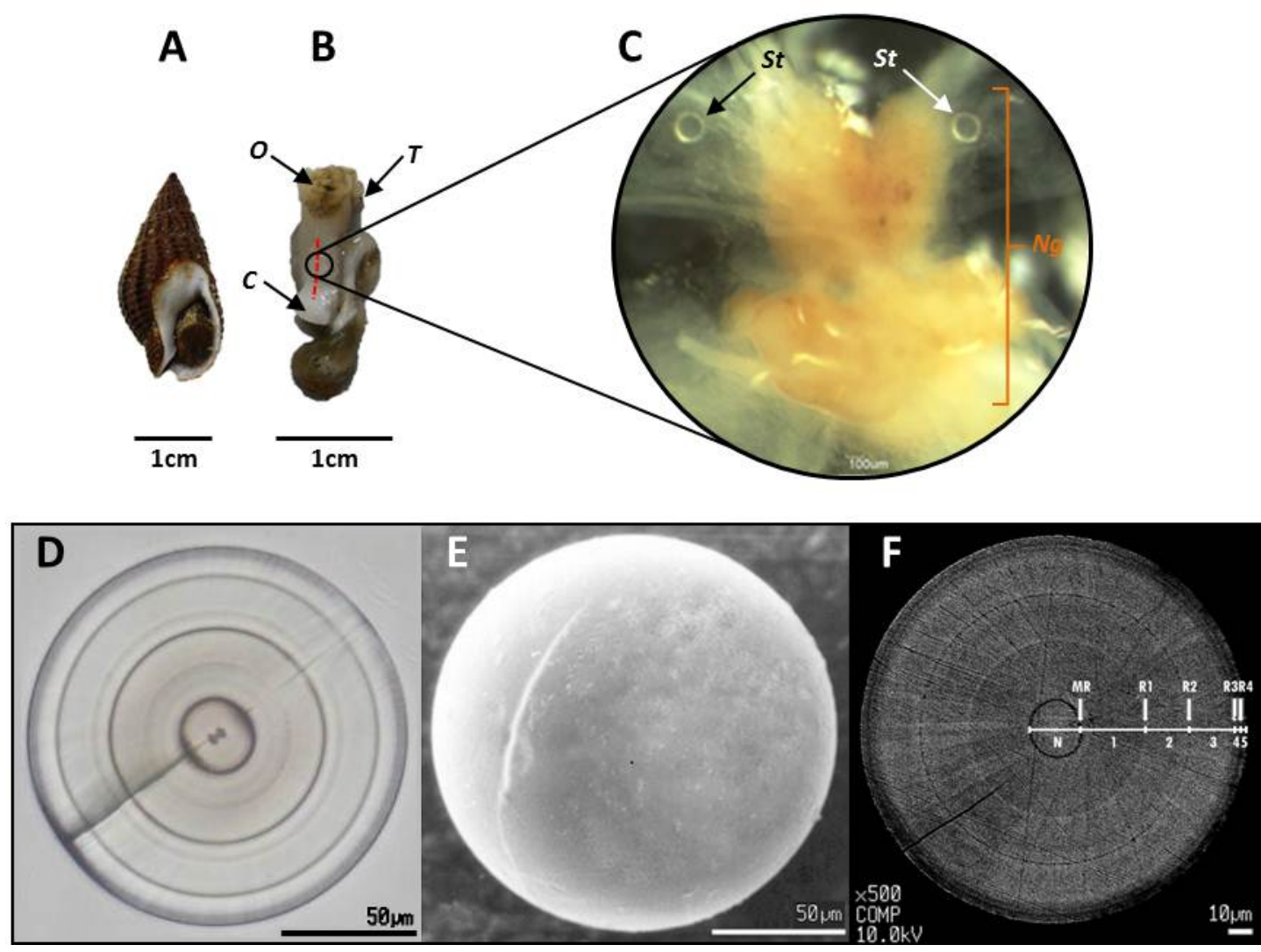

Figure 1.Nassarius reticulatus. (A) Ventral surface. (B) Specimen in ventral position after shell removal, indicating the cutting zone (dashed line) for statoliths extraction. (C) Nervous ganglia magnification and statoliths location. (D) Internal microstructure of a statolith grinded to its centerby OM. (E) External surface of a whole statolith by SEM. (F) COMP image of a statolith grinded to its center for EMPA analysis. $C$ : Columellar muscle; $M R$ : Metamorphic ring; $N$ : Nucleus; $N g$ : Nervous ganglia; $O$ : operculum; R1: First ring; R2: Second ring; R3: Third ring; R4: Fourth ring; St: statolith; T: Ocular tentacle.

Table 1. Standards, detection limits mean values (D.L.) and respective coefficient of variation (CV, i.e. Standard deviation/Mean) per element and statolith analysed (1,2 and 3). n.a.: not analysed.

\begin{tabular}{lllllllll} 
& Standard & & \multicolumn{2}{c}{ Statolith.1 } & \multicolumn{2}{c}{ Statolith.2 } & \multicolumn{2}{c}{ Statolith.3 } \\
\cline { 2 - 9 } Element & Name & Formula & D.L. & CV & D.L. & CV & D.L. & CV \\
\hline $\mathrm{Ca}$ & Calcite & $\mathrm{CaCO}_{3}$ & 410 & 0.06 & 380 & 0.08 & 400 & 0.08 \\
$\mathrm{Sr}$ & Tausonite & $\mathrm{SrTiO}_{3}$ & 222 & 0.02 & 221 & 0.02 & 211 & 0.04 \\
$\mathrm{Na}$ & Albite & $\mathrm{NaAlSi}_{3} \mathrm{O}_{8}$ & 192 & 0.08 & 193 & 0.06 & 159 & 0.07 \\
$\mathrm{~S}$ & Pyrite & $\mathrm{FeS}_{2}$ & 308 & 0.07 & 308 & 0.10 & 281 & 0.09 \\
$\mathrm{Mg}$ & Periclase & $\mathrm{MgO}$ & 170 & 0.09 & 168 & 0.07 & 121 & 0.08 \\
$\mathrm{Ba}$ & Barite & $\mathrm{BaSO}_{4}$ & n.a. & n.a. & n.a. & n.a. & 53 & 0.07 \\
$\mathrm{Al}$ & Orthoclase & $\mathrm{KAlSi}_{3} \mathrm{O}_{8}$ & n.a. & n.a. & n.a. & n.a. & 26 & 0.05 \\
$\mathrm{Cu}$ & Cuprite & $\mathrm{Cu}_{2} \mathrm{O}$ & n.a. & n.a. & n.a. & n.a. & 94 & 0.03 \\
$\mathrm{Hg}$ & Cinabrio & $\mathrm{HgS}_{\mathrm{SgS}}$ & n.a. & n.a. & n.a. & n.a. & 106 & 0.03 \\
$\mathrm{Sn}$ & Cassiterite & $\mathrm{SnO}_{2}$ & n.a. & n.a. & n.a. & n.a. & 48 & 0.04 \\
\hline
\end{tabular}

This work was supported by the Portuguese Foundation for Science and Technology (FCT) through the grant SFRH/BPD/70368/2010. 